\title{
DESENVOLVIMENTO DE UM CHOCOLATE COM MAIORES TEORES DE COMPOSTOS FENÓLICOS E SABOR PRÓXIMO AOS CHOCOLATES TRADICIONAIS
}

\author{
A. S. RECKEL ${ }^{1}$, G.T.CUZZUOL ${ }^{1}$, R. F. NASCIMENTO ${ }^{1}$, L.S.ARRIECHE ${ }^{2 *}$, D.J.M. SARTORI ${ }^{3}$ \\ C. M. N.YOSHIOKA ${ }^{2}$ \\ ${ }^{1}$ Bolsista PIVIC/Universidade Federal do Espírito Santo (CEUNES) \\ 2 Professor/DETEC/Universidade Federal do Espírito Santo (CEUNES) \\ ${ }^{3}$ Professor/DEQ/Universidade Federal de São Carlos (CCET) \\ *E-mail: leoarrieche@hotmail.com
}

\begin{abstract}
RESUMO - No processamento do chocolate, nas etapas de fermentação e secagem, é que ocorrem as maiores perdas de compostos fenólicos. Nesse sentido, o objetivo desse trabalho foi desenvolver um produto de chocolate que conserve a funcionalidade das amêndoas. Para tanto, utilizou-se da análise da secagem em leito fixo das amêndoas de cacau, por radiação solar e em estufa, bem como de análise granulométrica do açúcar utilizado nas formulações. As etapas utilizadas no processo foram previamente determinadas através de uma árvore de estados, com todas as possibilidades de etapas. A análise da secagem mostrou que esta etapa é totalmente regulada pela resistência à transferência de massa por difusão efetiva; o estudo da granulometria mostrou que é preciso tempos superiores a 6 horas de moagem; Dessa forma, o trabalho torna-se importante, pois contribui para a continuidade dos estudos sobre o processamento de chocolates artesanais com alto valor agregado.
\end{abstract}

\section{INTRODUÇÃO}

De acordo com EFRAIM et.al (2011), podemos encontrar compostos fenólicos em bebidas como vinho, chá verde e chá preto, e em frutas como maça, morango, cereja e ainda em amêndoas do cacaueiro. Os compostos fenólicos são produtos derivados do metabolismo secundário das plantas e são classificados como compostos aromáticos, sendo o próprio fenil o composto fenólico mais simples deste grupo. Após serem metabolizados pelo corpo humano, estes compostos atuam como antioxidantes impedindo a formação de radicais livres, ou ainda eliminando os mesmos através da doação do átomo de hidrogênio ligado ao anel aromático (SALVADOR, 2011). As inibições dos radicais livres no corpo protegem os constituintes celulares, de reações oxidativas, diminuindo a potencialização de doenças degenerativas causadas por stress oxidativo.

A quantidade de compostos fenólicos varia com as diferentes espécies de cacaueiros existentes. A espécie mais utilizada para a produção de chocolate é a Theobroma cacao, da variedade Forastero. De acordo com ZAMPIERI (2009), os principais compostos fenólicos encontrados nos cotilédones 


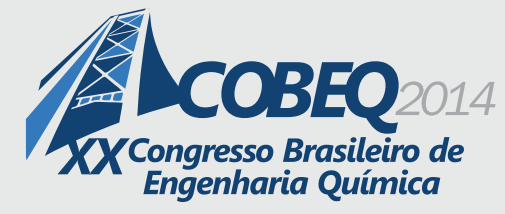

19 a 22 de outubro de 2014

Florianópolis/SC

desta variedade são catequinas, procianidinas, antocianinas, flavonóis glicosídicos além de clovamida e dideoxiclovamida, os compostos fenólicos chegam a representar cerca de 6 a $8 \%$ do total do peso seco de uma amêndoa, sendo $60 \%$ do total dos compostos, formados por catequinas.

Diferentes etapas são aplicadas às amêndoas de cacau para a produção do líquor, principal constituinte na produção do chocolate. Essas etapas consistem em corte do fruto, fermentação onde as amêndoas de cacau são postas em barcaças de madeira para ativar a ação das leveduras Saccharomyces cerevisae e Candida Krusei, possibilitando o desenvolvimento de precursores do sabor característicos do chocolate (OETTERER, 2006). Na sequência de etapas para à produção do líquor, ocorre à secagem, podendo ser artificial por meio de estufas ou natural via luz solar. Esta etapa é responsável por reduzir em uma faixa de 6 a 8\% à umidade, inibindo uma futura proliferação de fungos durante as próximas etapas. A etapa de torrefação consiste em uma nova secagem do fruto, porém nesta etapa a umidade chega a cerca de $2 \%$, e traços de ácido acético provenientes da fermentação são eliminados por evaporação. Ao final das etapas descritas, as amêndoas de cacau estarão prontas para o processo de moagem, implicado à redução granulométrica das partículas sólidas, nibs, até a estrutura mássica atingir um estado fluido de alta viscosidade ou consistência "pastosa".

Embora a principal matéria prima do chocolate seja rica em compostos fenólicos, o chocolate não apresenta os mesmos teores destes compostos em sua composição, isso se deve ao fator de perda durante as etapas do processamento para a fabricação do líquor. A ação das leveduras durante a etapa de fermentação favorecem reações de oxidação entre compostos aromáticos e enzimas do tipo polifenoloxidase e glicosidase, diminuindo a atividade antioxidante dos compostos em questão. Reações em etapas de fermentação podem ser responsáveis pela diminuição de até 70\% dos compostos fenólicos totais nas amêndoas de cacau. De acordo com EFRAIM (2010), perdas consideráveis ainda podem ser ponderadas em etapas posteriores a fermentação, principalmente na torrefação, onde tempo e temperatura de torra, são inversamente proporcionais a teores de polifenóis totais.

\section{OBJETIVO}

O presente estudo tem por objetivo, aprimorar técnicas do processamento do chocolate artesanal que possam aumentar o valor agregado do produto final e ainda determinar técnicas, que aplicadas ao processamento, possam favorecer a continuidade de compostos fenólicos no produto final, uma vez que etapas para a produção do líquor podem representar, perdas consideráveis no teor de compostos fenólicos presentes nas amêndoas de cacau, principal matéria prima do chocolate.

\section{METODOLOGIA}

Para o estudo da diminuição de perdas significativas dos compostos fenólicos, bem como, a avaliação de sua influência nas etapas de processamento e no produto final utilizou-se a seguinte metodologia: 


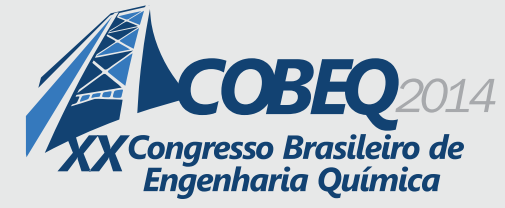

\subsection{Materiais e equipamentos}

Estufa, balança analítica, termômetro infravermelho, moinho de bolas de pequena escala em material de cerâmica, bolas em material de pedra de $15 \mathrm{~mm}$ de diâmetro cada, peneiras da série Tyler de 8, 20, 24, 35, 42, 48, 65 e 100 mesh, agitador de peneiras mecânico, liquidificador, recipientes de cerâmica esmaltada.

\subsection{Métodos}

O processamento do líquor de cacau, pode ser desempenhado por diversas possibilidades de etapas. A fim de determinar as etapas que melhor favorecem a permanência dos compostos fenólicos e o aumento do valor agregado do produto em estudo, desenvolvemos uma árvore de estados, apresentado em Figura 1, onde todas as etapas possíveis foram incluídas.

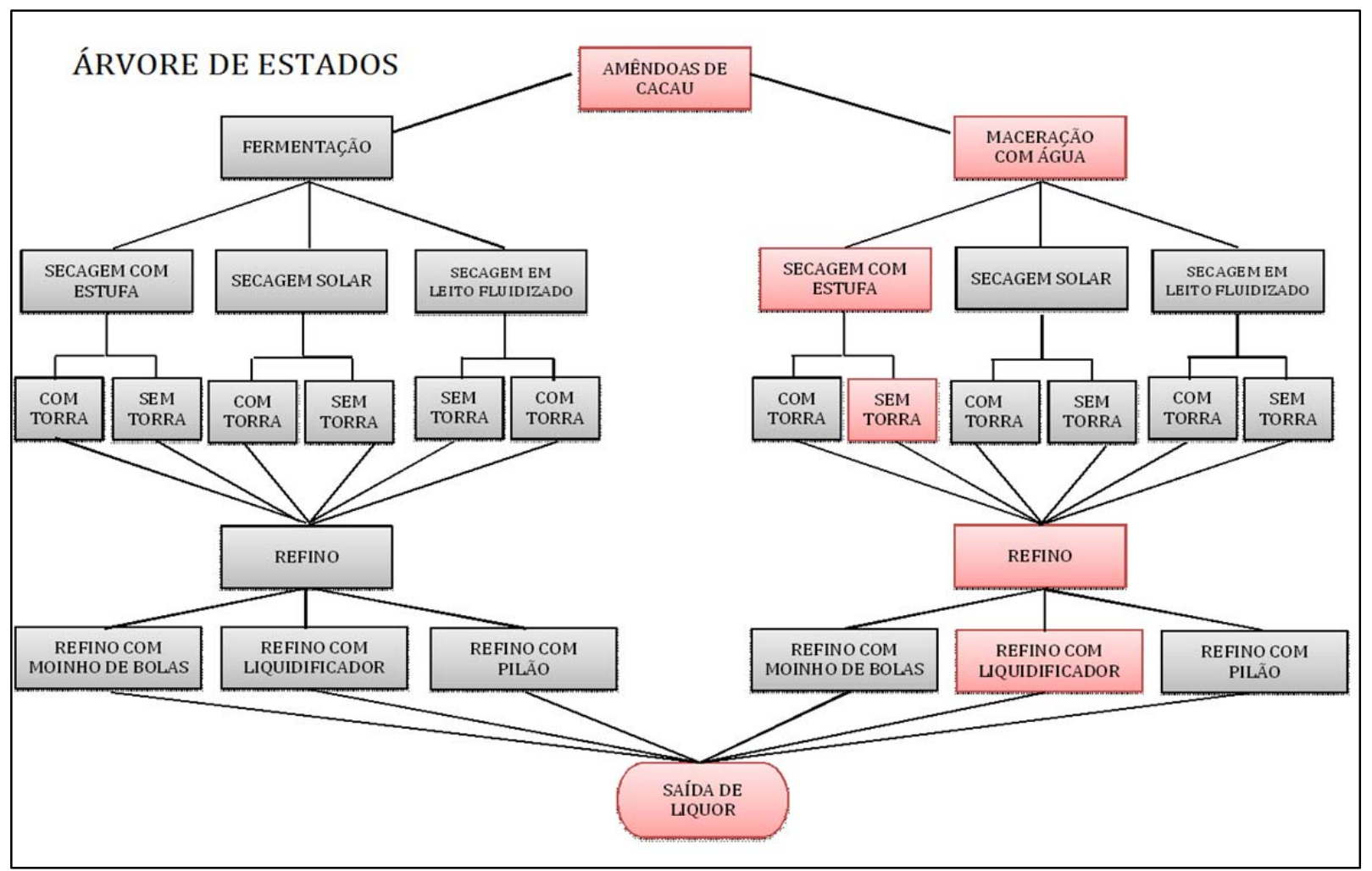

Figura 1: árvore de estados contendo as etapas do processamento do líquor.

Maceração: As amêndoas de cacau foram depositadas em um recipiente com água destilada, e maceradas até que todo o invólucro (polpa) das amêndoas fossem removidos. Ao término desta etapa as amêndoas apresentaram alto teor de umidade. 


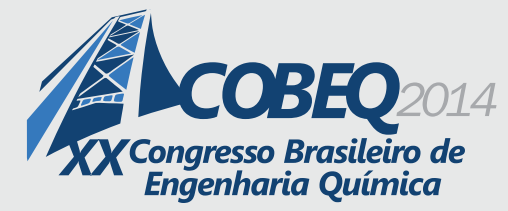

Secagem: As amêndoas tiveram sua massa inicial determinadas em uma balança analítica, e foram dispostas em leito fixo com proporções de $35 \mathrm{~cm}$ por $25 \mathrm{~cm}$. O método de secagem empregado na prática foi de secagem artificial, onde as amêndoas foram submetidas em calor constante em uma estufa com temperatura fixa de $70^{\circ} \mathrm{C}$ com oscilação de $\pm 3^{\circ} \mathrm{C}$. A amostra permaneceu na estufa até o peso das amêndoas se manterem constante (fator indicativo de umidade mínima), totalizando um tempo total de 1100 minutos. Durante os primeiros 540 minutos de secagem, a massa das amêndoas foi determinada em intervalos fixos de 15 minutos, para a especificação do decréscimo de umidade percentual.

$$
X=\frac{M_{u}-M_{S}}{M_{S}} \cdot 100
$$

A fim de ajustar a dependência linear do volume com a umidade, utilizamos um conjunto de equações que determina o encolhimento linear, onde toda a contração desenvolvida pela amostra é igual ao volume da água evaporada da sua estrutura, as equações que determinam este encolhimento estão aferidas abaixo.

$$
\begin{gathered}
V_{g}=V_{s}+V_{w} \\
\varepsilon=\frac{\rho_{s}}{\rho_{w}} \\
V_{g}=V_{S} \cdot(1+\varepsilon X)
\end{gathered}
$$

Diminuição granulométrica do açúcar: Para a redução granulométrica do açúcar cristal foi utilizado a técnica de moagem por meio do moinho de bolas. Durante o procedimento de moagem foram adicionados ao moinho 1000 gramas de açúcar cristal, juntamente com 50 bolas de pedra com $15 \mathrm{~mm}$ de diâmetro cada. O processo totalizou um tempo de 4 horas, sendo que amostras de aproximadamente 50 gramas foram recolhidas em intervalos fixos de 30 minutos. Posteriormente foram realizados dois novos experimentos de moagem com tempo total de 6 e 12 horas para a verificação do comportamento reológico das partículas do açúcar.

As amostras recolhidas durante a moagem foram submetidas à técnica de peneiramento mecânico, com um agitador de partículas composto por peneiras da série Tyler de 8, 20, 24, 35, 42, 48, 65 e 100 mesh, para determinação da redução do diâmetro de Sauter (CREMASCO, 2012) em função do tempo.

$$
d p_{s}=1 /\left(\sum_{i=1}^{n}\left(\frac{x_{i}}{D_{i}}\right)\right)
$$

Formulação: Para o desenvolvimento da formulação do protótipo, tomamos como base um chocolate padrão sem lactose. A partir das informações nutricionais deste chocolate padrão, foi 


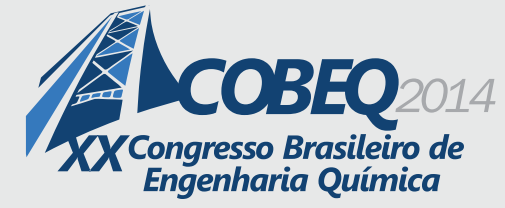

19 a 22 de outubro de 2014

Florianópolis/SC

possível determinar uma função objetivo e suas determinadas restrições para a utilização do balanço de massa, o sistema linear foi resolvido pelo software Microsoft Office Excel e ao final do processo de programação linear alcançamos a quantidade mássica de cada ingrediente a ser utilizado (SILVA, 2012).

Processo de conchagem e temperagem: $\mathrm{O}$ processo de conchagem consistiu em homogeneizar os ingredientes constituintes do chocolate, sob aquecimento constante sob uma faixa de temperatura de 40 à $80^{\circ} \mathrm{C}$, para a eliminação de voláteis indesejados e possibilitando a fluidez da mistura. Após este aquecimento a mistura foi submetida a etapa de temperagem, para que a massa de chocolate atingisse a faixa de temperatura entre 40 e $45^{\circ} \mathrm{C}$, possibilitando à formação e cristais estáveis.

\section{RESULTADOS}

\section{1. Árvore de estados}

As etapas seguidas durante o processamento do líquor, encontram-se assinaladas de vermelho na Figura 1. Por ser a etapa de fermentação responsável por quase $70 \%$ da perda dos compostos fenólicos, optamos por substitui-la, pela etapa de maceração em água, a fim de minimizarmos esta perda. O processo de secagem em estufa permite o controle total, sobre a temperatura nas amêndoas e ainda mostra-se menos susceptível a contaminações principalmente pela circulação do ar, ao contrário da secagem solar. Durante a etapa de secagem as amêndoas de cacau atingiram um nível de aproximadamente $8 \%$ de umidade, sendo o nível recomendável de 2\% após o processo de torrefação, para que problemas com fungos não venham atingir o produto futuramente durante o armazenamento. Como as amêndoas em estudo não necessitaram ser armazenadas, e objetivando a continuidade da concentração de compostos fenólicos, após a secagem, optamos por não utilizar a etapa de torrefação.

\subsection{Secagem}

Para a complementação do processo de secagem utilizamos o software image ${ }^{\circledR}$, um programa específico de análise de imagens. Durante toda a secagem, em intervalos de tempo fixos de 15 minutos, as amêndoas de cacau foram fotografadas. Com as imagens submetidas ao programa

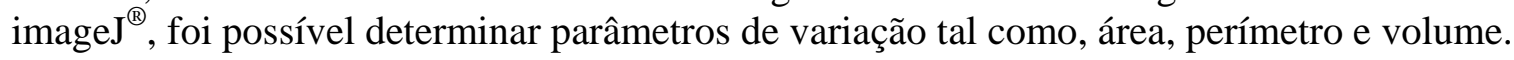

O gráfico mostrado na Figura 2, possibilita a visualização do decaimento exponencial de umidade percentual, em função do tempo, conseguido por pontos obtidos na prática de secagem, sendo esta umidade calculada de acordo com a Equação 1. O último ponto representa a massa seca onde o nível de umidade atingiu o mínimo. Com as Equações 2, 3 e 4 foi possível calcular o volume das amêndoas de cacau, o decréscimo do volume em função da umidade, durante o processo de secagem, pode ser visualizado no gráfico apresentado na Figura 3. Ao final do processo de secagem a redução do volume representou cerca de 42,21\% do total da massa inicial. 


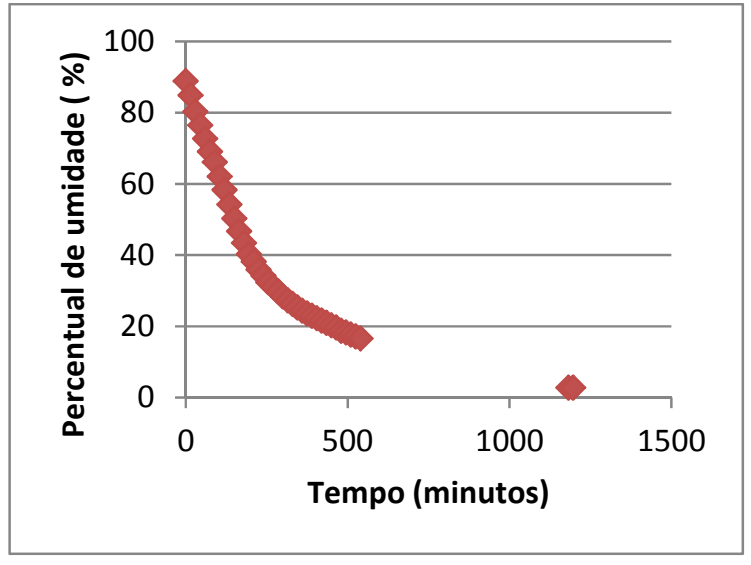

Figura 2: Percentual de umidade nas amêndoas de cacau em função do tempo.

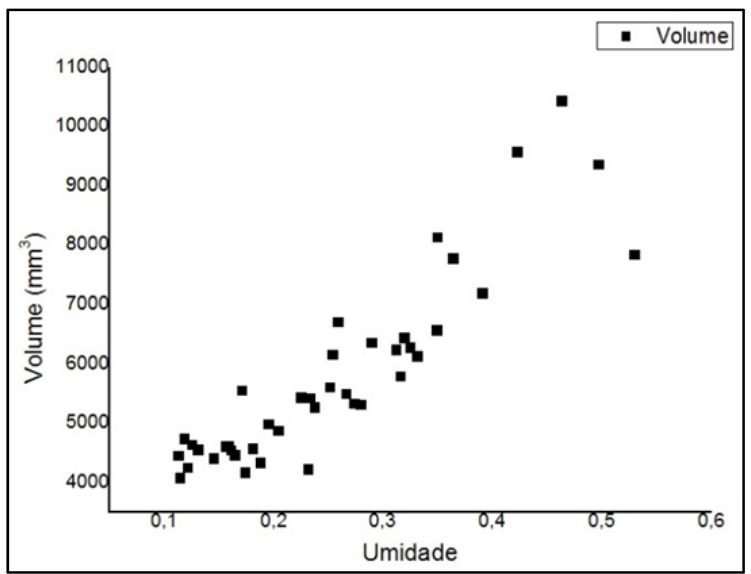

Figura 3 - Volume equivalente em função da umidade em base seca

\subsection{Diminuição granulométrica do açúcar}

De acordo com os dados fornecidos pela Tabela 1 e o gráfico apresentado em Figura 4 (obtidos através da etapa de moagem), é possível observar que o $\boldsymbol{d} \boldsymbol{p}_{\boldsymbol{s}}$ obteve uma taxa de redução de 0,355 mm em um intervalo de tempo de apenas 120 minutos. Porém observa- se ainda na tabela, que com um tempo de 360 minutos é possível obter uma taxa de redução de $\boldsymbol{d} \boldsymbol{p}_{\boldsymbol{s}} 0,358 \mathrm{~mm}$, um percentual de $0,85 \%$ maior, comparado ao intervalo de tempo de 120 minutos. No processo de moagem com intervalo de tempo 720 minutos é possível observar uma variação crescente no valor do $\boldsymbol{d} \boldsymbol{p}_{\boldsymbol{s}}$. Isso pode ser explicado pela mudança nas características reológicas do material particulado, que passa a atuar como um fluido não newtoniano, ou pela possível aglomeração das partículas causada pela decomposição do açúcar. O açúcar ao final de todos os processos de moagem apresentou- se com aspecto visual de um pó muito fino, semelhante ao talco.

Tabela 1 - Diâmetro médio de Sauter para moagem de açúcar cristal, contendo 50 bolas de 15 mm e1000 gramas de amostra.

\begin{tabular}{cc}
\hline Tempo moagem (min) & $\begin{array}{c}\text { Diâmetro mélio de } \\
\text { Sauter (mn) }\end{array}$ \\
\hline 0 & 0,506 \\
30 & 0,402 \\
60 & 0,216 \\
90 & 0,183 \\
120 & 0,151 \\
150 & 0,153 \\
180 & 0,230 \\
210 & 0,196 \\
240 & 0,192 \\
\hline
\end{tabular}

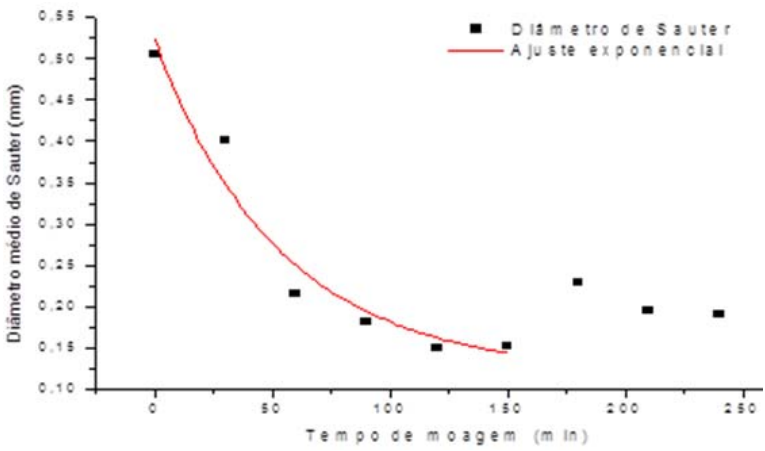

Figura 4 - Diâmetro médio de Sauter para moagem de açúcar cristal, contendo 50 bolas de 15 mm e 1000 gramas de amostra. 


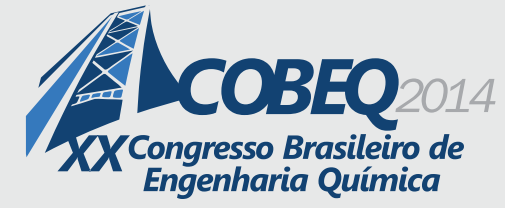

\subsection{Processo de conchagem e temperagem}

A faixa de temperatura estabelecida para o processo de conchagem não ultrapassou a temperatura de $80^{\circ} \mathrm{C}$, para que as perdas de compostos fenólicos fossem mínimas, uma vez que em altas temperaturas esses compostos são capazes de reagir com outros constituintes do líquor de cacau, inibindo suas funções antioxidantes. Durante o processamento da primeira amostra as etapas de conchagem e temperagem foram realizados 2 vezes. No processamento da segunda amostra as mesmas etapas de conchagem e temperagem foram realizados 4 vezes. O aumento do número de conchagem e temperagem realizados influenciou diretamente a reologia do produto final. A segunda amostra apresentou brilho, menor arenosidade, devido a maior homogeneização da mistura e apresentou ainda resistência a temperatura ambiente ao contrário da primeira amostra. As figuras 5 e 6 mostram a diferença visual entre os dois protótipos.

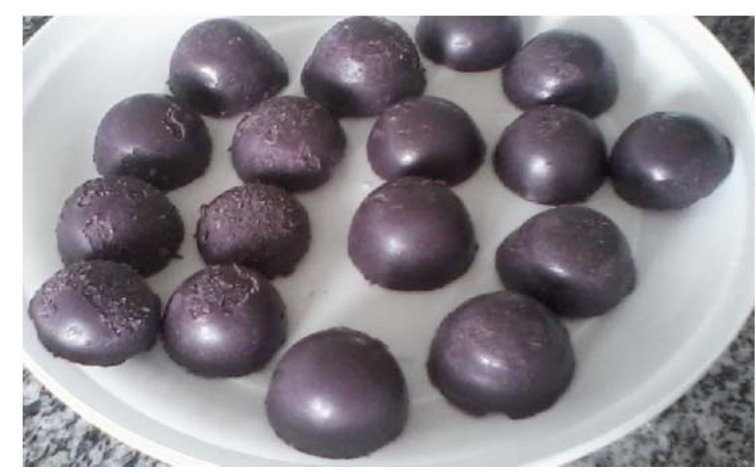

Figura 5: Primeira amostra do protótipo do chocolate

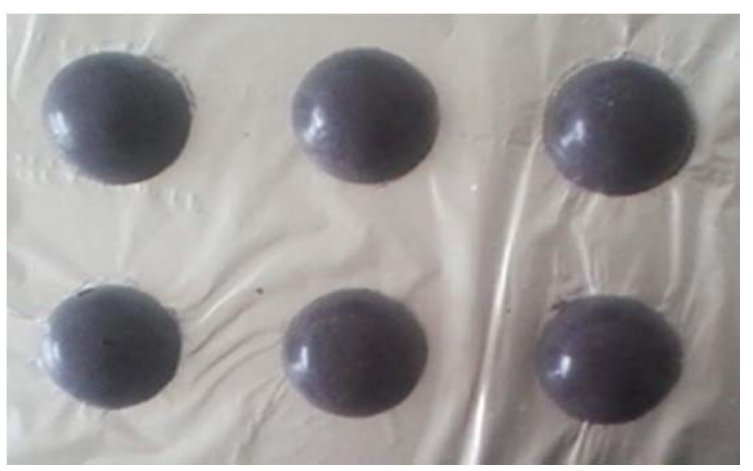

Figura 6: Primeira amostra do protótipo de chocolate

\section{CONCLUSÃO}

O processo de moagem, com tempo de 360 minutos, empregado para a fabricação do chocolate mostrou-se eficiente para a diminuição granulométrica das partículas do açúcar cristal, porém o protótipo apresentou-se ainda, com textura arenosa, ocasionado pelo diâmetro das partículas presentes. Sendo o açúcar constituinte de aproximadamente $50 \%$ da massa do chocolate, o açúcar necessita atingir ainda, menores valores do diâmetro médio de Sauter. Por observação dos protótipos como em Figuras 5 e 6, concluímos que as amostras continham alto teor de compostos fenólicos, uma vez que a intensa coloração roxa indica a presença destes antioxidantes.

As etapas escolhidas de acordo com a árvore de estados apresentada em Figura 1 mostraram-se eficientes para obter chocolates com maiores teores de compostos fenólicos. Os procedimentos repetidos de conchagem e temperagem realizados sob temperaturas controladas, repetidas vezes contribuíram para a maior estabilidade do protótipo, essa característica pode ser atribuída a melhor homogeneização dos constituintes da massa do chocolate, permitindo uma maior interação molecular entre as partículas, tornando o chocolate mais resistente a variações de temperatura. 


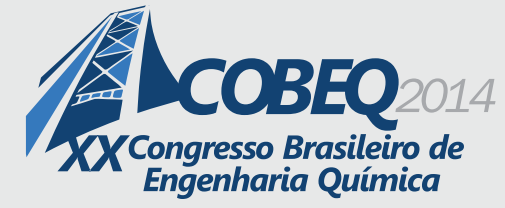

Contudo ainda é possível desenvolver um açúcar com menor diâmetro de Sauter que proporcione ao chocolate melhores características reológicas. A análise sensorial, bem como o desenvolvimento de métodos que possam quantificar o teor de compostos fenólicos, são indicados para a continuidade de estudos de chocolates com maiores teores de compostos fenólicos e maior valor agregado.

\section{NOMENCLATURAS}

$\boldsymbol{M}_{\boldsymbol{u}}$ Massa úmida, g

$\boldsymbol{V}_{\boldsymbol{g}}$ volume das amêndoas, $\mathrm{cm}^{3}$

$\boldsymbol{M}_{\boldsymbol{s}}$ Massa seca, g

$\boldsymbol{V}_{\boldsymbol{s}}$ volume de sólido, $\mathrm{cm}^{3}$

$\boldsymbol{X}$ Percentual de umidade

$\boldsymbol{d} \boldsymbol{p}_{\boldsymbol{s}}$ Diâmetro médio de Sauter, mm

$\boldsymbol{x}_{\boldsymbol{i}} \quad$ Fração mássica relativa à partícula de diâmetro i

$\boldsymbol{D}_{\boldsymbol{i}} \quad$ Diâmetro da partícula, cm

\section{REFERÊNCIAS}

CREMASCO, M. A. Operações Unitárias em Sistemas Particulados e Fluidomecânicos. São Paulo: Edgar Blucher, 2012. p. 126-157.

EFRAIM, P., PEZOA-GARCÍA, N. H., JARDIM, D. C. P., NISHIKAWA, A., HADDAD, R., EBERLIN, M. N. "Influência da fermentação e secagem de amêndoas de cacau no teor de compostos fenólicos e na aceitação sensorial”. Ciência e Tecnologia em Alimentos. v. 30. supl. 1. Campinas, maio, 2010.

OETTERER, M.; REGITANO, D.; SPOTO, M. A. B.;Fillet. M. H.; Fundamentos de ciência e tecnologia de alimentos. São Paulo- Barueri, 2006. Manole, 612 .

SALVADOR, I. Atividade antioxidante e teor de resveratrol em cacau, chocolates, achocolatados em pó e bebidas lácteas achocolatadas. 2011. Dissertação. Universidade de São Paulo- Centro de energia nuclear na agricultura.

ZAMPIERI, D. F. Influência de proteínas do leite na ação antioxidantes de flavanóis em chocolate. 2009. Dissertação. Universidade estadual de Londrina- Centro de ciências agrárias, departamento de ciência e tecnologia de alimentos. 